\title{
INVESTIGATING MOOC PLATFORMS AS A PROSPECTIVE TOOL FOR MOBILE LEARNING
}

\author{
Albena Antonova and Boyan Bontchev \\ Faculty of Mathematics and Informatics, Sofia University \\ 5, James Baucher Blvd., 1164 Sofia, Bulgaria
}

\begin{abstract}
The Massive Open Online Courses (MOOCs) provides new m-learning solutions for "learning-on-the-go", packing in one educational content, pedagogical framework and community support. Reaching millions of users world-wide, the MOOCs have the potential to fully transform educational landscape. However, the spread of the MOOCs is still limited, the retention rate and the degree of completion is small and the MOOCs efficiency remain doubtful. Thus, the present research aims to make an overview of the recent developments in MOOCs and m-learning solutions to recommend strategies for prospective learning providers. Considering the opportunities, it investigates suitable approaches for learning institutions to design and deliver m-learning MOOCs that will empower learners' experience. The paper is structured as follows. On first place, it makes an introduction to the MOOCs main concepts and identifies common features and classifications. Then, a short overview is made on the most popular MOOCs platforms. After that, the paper analyzes the MOOCs providers' approaches, including learners, technologies, instructional design, factors of success and lessons' learned of the MOOCs implementation. Finally, the discussion makes an overview of the steps and recommendations for implementing a successful MOOC.
\end{abstract}

\section{KEYWORDS}

MOOC, User-Centered Learning, M-Learning, MOOC Learning Provider

\section{INTRODUCTION}

The Massive Open Online Courses (MOOCs) build on the long history of the distance education, boosting knowledge democratization and access to learning. In addition to the wide spread of mobile technologies, the MOOCs promise to improve the access to learning for anyone, anytime and anyplace. Facilitated by m-learning technologies, it can combine a large set of solutions for learning-on-the-go, promoting personalized and situated mobile learning (Kukulska-Hulme, 2009), bridging formal and informal learning experiences, virtual collaboration and communication (Duncan-Howell and Lee, 2007). Aiming to be both open and massive, today MOOCs involve millions of learners across the world and include hundreds of MOOCs technology platforms. Even more, thousands of MOOCs courses are produced by the most renown universities, learning providers, technology institutions and not-for-profit organizations. Combined, m-learning and MOOCs are two developments with the potential to fundamentally reshape the landscape of education. However, there are still many technical, educational and social challenges for learning providers in order to guarantee equal access to education for all (Sharples et al. 2015). More importantly, the efficiency of the MOOCs courses is small, the drop-out rate of the learners is high, and many employers are still skeptic about the effectiveness of the MOOCs, finding them superficial, too general, and incomparable with traditional learning. Therefore, learning providers have to be better prepared to design appropriate MOOCs solutions, considering MOOCs platforms, pedagogical methods and learners' experiences.

The present research aims to make an overview of the MOOCs recent developments for prospective learning provider, in order to derive to structured recommendations for design and delivery of learner-oriented course offerings. Considering portable m-learning solutions, it will investigate strategies for developing m-learning MOOCs, reflecting on the MOOCs functions, application fields, and learners' experiences, focusing on features, tools and functionality to support knowledge transfer. 
The paper is structured as follows. On first place, it makes an introduction to the MOOCs main concepts, common features and classifications, and characteristics of the MOOCs platforms. Then, the paper investigates the main specifics of the MOOCs implementation, taking into account the learners, the learning process and MOOCs technologies and institutions. Finally, the discussion presents practical recommendations for MOOCs users. The conclusion outlines the next directions for implementing successful m-learning and portable MOOCs.

\section{BACKGROUND - MOOC DEFINITION AND CHARACTERISTICS}

Hollands and Tirthali (2014) define MOOCs as online courses that: "allow hundreds of thousands of students to participate simultaneously in a course and are free and open to any interested participant ...". The main characteristics of MOOCs remain the open access (anyone can participate) and scalability (supporting indefinite number of learners). The term MOOC was first used in 2008 to describe the online course "CCK08: Connectivism and Connective Knowledge" (Downes, 2008). This is the first example of a course, where twenty-five students taking the course for fee and for credit are accompanied by another 2,300 'open' participants. This first MOOC was delivered as an "open" and "massive" course, providing both course materials and a certificate of completion free of charge. Few years later, in 2011, the lecture "Introduction to Artificial Intelligence" of Thrun from Stanford University reached over 160000 enrolled students (Kopp and Lackner, 2014). The both courses are online courses, massively attended and open to everybody. Since then, the number of MOOCs increased tremendously worldwide, stimulated largely by the emergence of the popular MOOC platforms (Yuan \& Powell, 2013).

\subsection{Classification and Categories of MOOCs}

The majority of the MOOC categorisations were created from the viewpoint of a MOOC providers and cover issues such as the number of participants, the degree of openness and pedagogy (Liyanagunawardena et al., 2019). During the years, the main categories of MOOCs are defined as: cMOOCs (based on connectivism) and xMOOCs (based on behaviorism). The main difference between these two MOOCs types lies in their didactic approach (Kopp and Lackner, 2014). First, the cMOOCs are built on the connectivist learning theory, valuing interaction within the community, social media interaction and peers' discussions. It facilitates learning in the network and encourages participants to create, share, and reflects upon each other's artifacts (such as videos, blog posts and others). Second, the xMOOCs are delivered as an "extension" of the traditional learning environment, providing education at scale. Thus, xMOOCs reproduce online the traditional lecture: video lectures, computer-based assignments and tests, and peer assessment. It is media- or teacher-centered, focusing on instruction and delivery of content usually from professors by prestigious institutions, such as Harvard and Stanford (Daniel, 2012). Today, the vast majority of existing MOOCs classifies as xMOOCs. The MOOC classification of Pilli and Admiraal (2016) focuses on the level of which a MOOCs is Massive and Open. They define four cases: (1) Small scale/less open courses (limited enrolments and a fee); (2) Small scale/ more open, (free courses with limited enrolment); (3) Large scale/less open (courses with some course material freely available, but restricted access to other material and assessments); (4) Large scale/more open (content is freely available to all).

Working on a MOOCs taxonomy, Clark (2013) suggested a taxonomy from a pedagogical perspective oriented to MOOC delivery methods. Liyanagunawardena et al. (2019) made a review of different MOOCs classifications and made the following proposal. They defined 13 common categories for every MOOC: (a) brief description; (b) syllabus; (c) subject area; (d) educators; (e) institution; (f) supporter; (g) provider; (h) timings; (i) pre-requisites; (j) certification; (k) cost; (l) reviews; and (m) language. As well, the authors analyzed how each of the MOOC providers and aggregators match each of these 13 categories.

\subsection{MOOCs Platforms}

The raising MOOCs' popularity is due to the large number of MOOCs platforms, divided on MOOCs aggregators and MOOCs content providers. The MOOCs platforms collect and provide information about the MOOCs courses in a learner-oriented form. In general, MOOCs platform can classify on MOOCs aggregators 
and MOOCs providers. For instance, the MOOCs aggregator services focus on course ratings and reviews; while in contrast, the MOOCs providers address specific course details such as openness of the MOOCs, course pre-requisites and available certificates. The mobile app market places, such as Google Play and iTunes host numerous educational apps for m-learning MOOCs solutions. However, the massiveness of the MOOCs, including statistics and popularity, is not reflected neither by the MOOCs providers nor by the aggregators.

\subsubsection{MOOCs Aggregators}

The aggregator services aim to collect in one place courses from several MOOCs providers. This facilitates prospective participants to navigate through the courses of different MOOCs providers, exploring extensive search options and specific categories, generated by the aggregator services (Table 1). For example, on the MOOC aggregator listed last - MOOC List, there are currently available courses on 32 languages, provided by universities and learning institutions from 61 countries.

Table 1. The most popular MOOCs aggregators (data from aggregators' websites, March 2020)

\begin{tabular}{lll}
\hline Name & Website & Features \\
\hline Classcentral & https://www.classcentral.com/providers & 45 MOOCs providers \\
Coursebuffet & https://www.coursebuffet.com/providers & 16 MOOCs providers \\
Coursetalks & https://www.coursetalk.com/providers & 46 MOOCs providers \\
MOOC List & https://www.mooc-list.com/ & 77 MOOCs providers \\
\hline
\end{tabular}

\subsubsection{MOOCs Content Providers}

The majority of the MOOCs are delivered via MOOC content providers, even developed by leading academic institutions. Coursera, edX, and Udacity were the first major MOOC platforms, based in North America. Today, many MOOC providers come from Europe such as EMMA (European Multiple MOOC Aggregator), FutureLearn (UK), iversity (DE), MOOIN (DE) and iMooX (Austria). While initially the MOOC platforms supported only English, now many MOOC platforms are multilingual. Other language MOOCs are Edraak (Arabic), MiriadaX (Spanish and Portuguese) and XuetangX (Chinese).

Furthermore, some governments promoted national-wide MOOCs platforms, such as the platform France Université Numérique (FUN) and platform MéxicoX. Even more, Finland, recognizing the role of Artificial Intelligence, organized a specialized MOOC platform for AI training (https://course.elementsofai.com/) first, providing it on Finnish and English, and lately, translating it on all other EU languages.

Table 2. The numbers of learners, courses and degrees of MOOCs providers (data from Classcentral, 2019)

\begin{tabular}{lllll}
\hline Name & Learners & Courses & Degrees & Mobile app \\
\hline Coursera & 45 million & 3800 & 16 & $\mathrm{X}$ \\
edX & 24 million & 2640 & 10 & $\mathrm{X}$ \\
Udacity & 11.5 million & 200 & 1 & Not available \\
FutureLearn & 10 million & 880 & 23 & Not available \\
Swayam & 10 million & 1000 & 0 & $\mathrm{X}$ \\
\hline
\end{tabular}

In Table 2, there are presented some of the main figures for the top $5 \mathrm{MOOC}$ content providers, as identified by the aggregator Class central for 2019 and including the number of learners and number of courses. Based on its statistics, for 2019 the course topics by subject are distributed as follows: Technology $(19,8 \%)$, Business $(19,7 \%)$, Social Sciences $(11 \%)$, Science $(9 \%)$, Humanities $(8,9 \%)$, Education and teaching $(8 \%)$, Engineering $(7,8 \%)$, Health and medicine (7,4\%), Arts and Design (5,2\%), and Mathematics (2,9\%).

\subsubsection{MOOCs m-Learning Platforms}

The m-learning solutions for MOOCs increasingly gain popularity, exceeding tens of millions of downloads. The most popular m-learning MOOCs providers are still Coursera and edX, but Udemy and LinkedIn Learning emerge as increasingly popular mobile learning platforms (Table 3). All these platforms support Android, iPhone, and iOS mobile devices. 
Table 3. The most popular MOOCs mobile platforms (data from Google Play and iTunes, March 2020)

\begin{tabular}{lllll}
\hline Name & Courses & $\begin{array}{l}\text { Installs } \\
\text { Google Play }\end{array}$ & $\begin{array}{l}\text { Reviews/ } \\
\text { Google Play }\end{array}$ & $\begin{array}{l}\text { Reviews/ } \\
\text { iTunes }\end{array}$ \\
\hline Udemy & $>2000$ topics & 10 Mio + & $194,6 \mathrm{~K}$ & $17 \mathrm{~K}$ \\
& $>130000$ videos & & $4,5 / 5$ & $4,6 / 5$ \\
\hline Coursera & $>2000$ & 5 Mio + & $\begin{array}{l}99,45 \mathrm{~K} \\
4,3 / 5\end{array}$ & $\begin{array}{l}54,8 \mathrm{~K} \\
4,8 / 5\end{array}$ \\
\hline edX & 2000 & 1 Mio + & $56,31 \mathrm{~K}$ & $2,8 \mathrm{~K}$ \\
& & & $4,7 / 5$ & $4,7 / 5$ \\
\hline LinkedIn & $>4000$ & 1 Mio+ & $18,7 \mathrm{~K}$ & $47 \mathrm{~K}$ \\
learning & & & $4,6 / 5$ & $4,8 / 5$ \\
\hline Khan Academy & Students/ & 10 Mio+ & $114,4 \mathrm{~K}$ & $4,9 \mathrm{~K}$ \\
& Teachers & & $4,5 / 5$ & $4 / 5$ \\
\hline
\end{tabular}

For example, Udemy attracts learners with access to more than 2000 courses on wide number of topics, provided by more than 50000 instructors, teaching on more than 60 different languages. The Udemy platform supports course downloads, audio-only mode, video streaming, learning personalization and speed control. The mobile application of Coursera allows learners to browse courses in a variety of subject areas. It supports both online streaming of video lectures and downloads for offline viewing. The edX mobile platform promotes the access to wide range of online classes, quizzes and exams, supporting extended search functions. LinkedIn Learning offer another m-learning approach, allowing learners to download courses for offline viewing, to share courses with the network and to add certificates of completion into LinkedIn profile. Finally, Khan Academy is an application, designed mainly for secondary school students, however gaining attention of adult learners by providing free courses and thousands of interactive exercises, videos, and articles.

\section{INVESTIGATING MOOC SPECIFICS}

\subsection{Defining MOOCs Learners' Profile}

The MOOCs learners' profiles largely vary across courses, countries and subjects. In general, the MOOCs audience is widely heterogeneous, and can include multiple learning profiles, such as students, academics, employees, unemployed and retirees, all having different motivation, learning approaches and expectations. However, the studies reveal that $70 \%$ to $80 \%$ of the MOOC participants are already well-educated with at least a B.A. degree (Hollands \& Tirthali 2014; Kopp and Lackner 2014). Even the participants from emerging countries belong to the educated and wealthy part of society. As Fyle (2013) concludes, besides technical infrastructure, the learners in MOOCs should have specific soft skills, including strong academic self-concept, good interpersonal and communication skills, basic understanding of collaborative learning, self-directed learning skills and cognitive learning strategies. In informal learning settings, for achieving one's own learning goal, the willingness to learn is supported by discipline to cope with autonomous, self-directed, self-organized and self-paced learning processes and good time management (Lackner et al., 2015). All this reduces the chances for people of limited educational background and experience to join MOOCs.

\subsubsection{Learners' Drop Out}

The numerous drop-outs and the small success rate (below 10\%, most often 7,5\%) of successful MOOCs learners are largely discussed in the literature. Lackner et al. (2015) classify the reasons for dropping out of a MOOC within two categories: personal (internal), and imposed (external). First, in adult learning a difference should be made between learning for personal and for professional purposes. Whereas professional purposes are often externally motivated, linked to enterprises and to the labor market, it is more difficult to identify and validate the personal purposes and internal motivations. The employers position on MOOCs, how they recognize the MOOCs certificates and their attitude can impact on the learners' motivation. Sometimes MOOC participants just "shop around" and pick up different elements of a course but do not want to finish the course itself; sometimes it is not the whole course that seems to be interesting but only parts of it. Thus, learning goal 
can differ from the objectives or learning outcomes, set up by the institution or the lecturers (Lackner et al., 2015). The success rate depends as well on the main antecedents of learning, including the students' prior experiences with education, their motivations, previous performance and perceived effectiveness in learning (Vigentini et al., 2016).

\subsubsection{Learning Engagement}

The individual's motivation to participate in a MOOC can largely vary from achieving an academic certification, to acquire specific skills, for personal enrichment and self-satisfaction. More recently, Deng et al. (2020) identifies four type of learners' engagement: behavioral, cognitive, emotional, and social engagement. Considering that most learners are university graduates, they can participate in MOOCs for variety of reasons, expecting different benefits, based on the MOOCs recognition and accreditation. The learners can be classified in three main groups (Alario-Hoyos et al., 2014b): (1) lurkers, who register in a course but never log in or enter without completing the tasks, (2) participants that do not complete the course, but take part in some activities and (3) participants that complete the course. In the empirical study of Alario-Hoyos et al. (2014b), the group of lurkers is the biggest one (26,5\% are no-shows and $42 \%$ are just observers). The participants, who completed successfully the course are about $8 \%$, among which engaged participants, who take all the assignments are only $6 \%$ from all enrolled. The most engaged participants used to act as mentors, assisting their peers and enriching the MOOC with additional content and discussion.

\subsection{The MOOC Learning Process}

The MOOCs learning process depends on the chosen form. Most of the xMOOCs are designed as weekly sequences of instruction, combining short video lectures punctuated with quizzes, supplemental readings and assignments. Thus, the learning process in the xMOOCs is structured in a linear way, building on the passive transmission-based learning strategy of the traditional classroom. Some courses allow learners to submit open assignment, but often the interaction between learners are limited to forum discussions. The learning process in cMOOCs aims to encourage participants to learn in the networks of people, tools, artefacts and organizations, reaching their individual and collective objectives (Tirthalli, 2016). The learning dynamic in cMOOCs is not one to many, but many to many, exploring learning as social and interactional, encouraging reflection, dialogue and collaboration, applying theory learnt to practice, creating community of peers, enabling creativity and motivating learners (Conole, 2013).

\subsubsection{Instructional design for MOOCs}

Building a MOOC is not an easy task, even for courses, based on an already existing and mature course. The inappropriate course design or the lack of a clear course structure can lead multiple learners to drop out. Kopp and Lackner (2014) find out that although the similarities, the design of the MOOCs courses actually differ from the other blended-, online- or m-learning methods. The main difficulty is that learners can come from different backgrounds, countries and social strata, making planning and designing increasingly challenging. Furthermore, Kopp and Lackner (2014) propose a checklist for the design and development phase of a MOOC, based on the ADDIE approach. Thus, instructional design process includes seven categories: core requirements, structure, participant requirements, assignments, media design, communication and resources. Conole (2013) discusses the 7C Learning Design framework for MOOCs, covering course Conceptualization (the vision for the course), Capture (a resource audit), Communicate (mechanisms to foster communication), Collaborate (mechanisms to foster collaboration), Consider (assessment strategies), Combine (overarching views of the design), and Consolidate (implementing and evaluating the design in a real learning context). Alario-Hoyos et al. (2014a) propose a MOOC Canvas as a simple and visual framework, facilitating educators to design a MOOC from scratch.

\subsubsection{Technologies}

Technologies offer many ways in which MOOCs can facilitate learning, such as interacting with multimedia or communicating and collaborating with peers. However, the MOOCs (and especially xMOOCs) do not need many features to be successful (Kopp and Lackner, 2014). It is the innovative combination of already known components like video lectures, forums and quizzes that make MOOCs special. This way, the MOOCs platform should contain the possibility to provide and to access videos, text transcripts, quizzes and further readings, a forum to communicate with other participants and a billboard, where news are announced. 


\section{A. Videos}

Videos play a central role for students' learning experience in the current generation of MOOCs. Guo et al. (2014) find out that videos have a big influence on the student engagement in MOOCs. Based on that, they formulate several practical recommendations for MOOCs creators: (1) to use short videos (up to 6 min); (2) to make post-production editing and to display slides together with the instructor's head; (3) to film in more informal setting, encouraging instructors to speak fairly fast and with high enthusiasm; (4) to produce Khan-style tablet drawing tutorials, that are more engaging than PowerPoint slides or code screencasts; (5) to introduce motion and continuous visual flow into tutorials, along with extemporaneous speaking; (6) to consider that students engage differently with lecture and tutorial videos and thus for tutorials, to add options for re-watching and skimming (Guo et al. 2014).

\section{B. Social tools}

The main social tools, used to connect the MOOCs' participants are the forums and social networks, either built-in tools, available on the platform, or external tools, provided by third-parties (such as social networks, forums, microblogging and others). In all cases, using appropriate social tools play an important role to effectively build connections among MOOC participants, facilitating mentors and peers to create a vibrant MOOC community. Thus all MOOCs need to ensure appropriate level of interactivity and collaboration (Gamage et al, 2020). Open-ended, guided, or directed peer-to-peer assessments of course tasks and projects appear the most important social tool for providing individual feedback, and for engaging and motivating course participants, without any need of instructor intervention (Staubitz et al., 2016).

\subsection{Motivation for Learning Institutions to Create MOOCs}

The main factors, motivating learning institutions to create MOOCs can largely vary (Tirthali, 2016). Usually, learning institutions reflect on MOOCs as tools to extend the reach and the access to education, to build and maintain the brand, to lower costs or increase revenues, to improve educational outcomes for MOOC participants and on-campus students, to innovate in teaching, learning and research (Hollands and Tirthali, 2014). There exist different strategies how learning institutions can adopt MOOCs courses in their learning offerings (Ebner et al., 2020). This way, many institutions can implement MOOCs to improve the quality of campus education, to increase the visibility of its brand and to open education to reach the global masses (Stöhr et al., 2015). However, MOOCs are expensive to produce (Tirthali, 2016), as it is a team effort, involving considerable amount of time and investments from faculty, teaching staff, instructional designers and videographers, graphic designers and programmers. Many institutions find out that MOOCs can bring additional revenue streams and not-direct benefits, such as savings for ongoing courses and increasing in the in-campus enrollments. Most often, the revenue from MOOCs come from delivering certificates and on-line degrees. However, it depends from the level that the learning institution can offer learning credits for MOOCs, making them equivalent to face-to-face or formal online courses.

\section{DISCUSSIONS}

The raising popularity of the MOOCs mobile platforms is expected to encourage more learning institutions to investigate strategies to successfully design and develop mobile MOOCs offerings. They need to take into account the following considerations, including both methodological and technological issues:

- First, taking into account that most of the MOOCs learners are University graduates, learning providers (LP) can design user-centered learning paths, recognizing learners' personal and professional motivations to engage in life-long-learning. As m-learning MOOCs require specific prior skills and motivation to enroll and to successfully complete, LPs can introduce personalization approaches, including course contextualization and adaptation in larger scale, reducing some common learners' barriers such as language, time constraints and cognitive overload.

- On second place, many statistics prove that teachers and lecturers are among the main group of the MOOCs learners, motivated to gain personal reward and a sense of intrigue and altruism (Hew and Cheung, 2014). Therefore, LPs can design specific learning paths for teachers and lecturers, allowing them not only to 
upgrade their professional knowledge and skills, but explicitly introducing pedagogical practices and teaching approaches that can be used later in face-to-face class interactions.

- Third, younger generations are increasingly expecting to interact with mobile learning, videos, and MOOCs in their formal and informal studies. Thereby, LPs should increasingly prepare for the raising demands and expectations for m-learning by the new generation of learners (Gómez-Ramirez et al, 2019).

- Fourth, the experience of xMOOCs and cMOOCs suggests that LPs should increasingly encourage passive learners to engage and interact with their peers (e.g., by forum discussions or peer assessments), to produce individually or in-group artefacts, and to reflect on their learning. Designing interactive exercises, building trust and sense of community and engaging in social discussions will increase the success of MOOCs learning and knowledge building. Especially for m-learning MOOCs, the mobile MOOC design should offer clear navigation, simple layout, liner display, and full interaction (Jia and Zhang, 2018).

- Fifth, due to the ever-growing popularity of mobile applications and m-learning, all MOOCs platforms should provide client applications at least for Android, iPhone, and iOS mobile devices. By applying appropriate adaptation to the smaller screen sizes of both the user interface and learning content, MOOCs mobile clients should support the same functionality as the Web clients. For example, they should provide learner dashboard, multi-screen support, discussion forums, peer-to-peer assessment, offline learning, and multi-language support.

- Finally, LP have to define appropriate strategies and criteria for selecting and implementing a MOOC platform. Thus, LP should consider the overall costs for installation, maintenance and management of the MOOC platform, including its mobile learning component. Furthermore, LP should define the platform functionality, including on-line/off-line video-and audio lectures, peer assessment, automatic quiz assessment, and supporting enough options for interactivity and collaboration (Gamage et al., 2020).

\section{CONCLUSION}

Increasingly, the MOOCs become accessed as mobile learning solution, improving the access and portability of learning. Supporting learners in all phases of learning, it facilitates pre-learning experience (browsing courses, enrolling), learning-on-the go (watching online video, making quizzes, downloading content), and post-learning experience (commenting, socializing, consulting content and recommendations, sharing learning artefacts). Therefore, building adaptable and contextualized mobile learning strategies is especially important for MOOCs learning providers. Furthermore, the MOOCs' experience can help a large group of learning providers to build better strategies for adopting e-learning, m-learning and blended learning approaches.

Nowadays, MOOCs are offered for both Web and mobile client applications, where upon difference between their functionalities become ever less essential. While the technological issues are steadily resolved by the modern mobile devices offering high resolution of display, higher performance, and faster mobile throughput, there are still some pedagogical and methodological concerns that will continue attracting the attention of MOOC designers in the next years. Future MOOCs should address the great percentage (up to $90 \%$ ) of learners dropping out due to lack of incentive, failure to understand the course content and having no help (Hew and Cheung, 2014), by offering a better personalization, contextualization, and adaptation to the knowledge and needs of each individual learner.

\section{ACKNOWLEDGEMENT}

The research in this paper is partially supported by The National Science Program "Information and Communication Technologies for Unified Digital Market in Science, Education and Security" financed by the Ministry of Education and Science, Bulgaria. 


\section{REFERENCES}

Alario-Hoyos, C., Pérez Sanagustín, M., Cormier, D. and Delgado Kloos, C., 2014. Proposal for a conceptual framework for educators to describe and design MOOCs. In J. of Universal Computer Science, vol. 20, no. 1 (2014), pp.6-23.

Alario-Hoyos, C., Pérez-Sanagustín, M., Delgado-Kloos, C. and Munoz-Organero, M., 2014. Delving into participants' profiles and use of social tools in MOOCs. In IEEE Transactions on Learning Technologies, 7(3), pp.260-266.

Clark, D. 2013. MOOCs: taxonomy of 8 types of MOOC. Donald Clark Plan B, Blog post. Retrieved from http://donaldclarkplanb.blogspot.co.uk/2013/04/moocs-taxonomy-of-8-types-of-mooc.html

Conole, G.G., 2013. MOOCs as disruptive technologies: strategies for enhancing the learner experience and quality of MOOCs. In Revista de Educación a Distancia, (39).

Daniel, J., 2012. Making sense of MOOCs: Musings in a maze of myth, paradox and possibility. In Journal of interactive Media in education, 2012(3).

Deng, R., Benckendorff, P. and Gannaway, D., 2020. Learner engagement in MOOCs: Scale development and validation. British Journal of Educational Technology, 51(1), pp.245-262.

Downes, S., 2008. Places to go: Connectivism \& connective knowledge. Innovate. In J. of Online Education, 5(1), p.6.

Duncan-Howell, J.A. and Lee, K.T., 2007. M-Learning-Innovations and Initiatives: Finding a place for mobile technologies within tertiary educational settings. Ascilite.

Ebner, M., Schön, S. and Braun, C., 2020. More Than a MOOC-Seven Learning and Teaching Scenarios to Use MOOCs in Higher Education and Beyond. In Emerging Technologies and Pedagogies in the Curriculum (pp. 75-87). Springer, Singapore.

Gamage, D., Perera, I. and Fernando, S., 2020. MOOCs lack interactivity and collaborativeness: Evaluating MOOC platforms. International Journal of Engineering Pedagogy (iJEP), 10(2), pp.94-111.

Gómez-Ramirez, I., Valencia-Arias, A. and Duque, L., 2019. Approach to M-learning Acceptance Among University Students: An Integrated Model of TPB and TAM. International Review of Research in Open and Distributed Learning, 20(3).

Guo, P.J., Kim, J. and Rubin, R., 2014, March. How video production affects student engagement: An empirical study of MOOC videos. Proceedings of the first ACM conference on Learning@ scale conference, pp. 41-50.

Fyle, C.O., 2013, June. Teacher education MOOCs for developing world contexts: Issues and design considerations. Proc. of Sixth International Conference of MIT's Learning International Networks Consortium (LINC).

Jia, J., and Zhang, B. (2018, July). Design Guidelines for Mobile MOOC Learning-An Empirical Study. Proc. of Int. Conference on Blended Learning, Springer, Cham., pp.347-356.

Hew, K. F., and Cheung, W. S. (2014). Students' and instructors' use of massive open online courses (MOOCs): Motivations and challenges. In Educational research review, 12, pp.45-58.

Hollands, F.M. and Tirthali, D., 2014. MOOCs: Expectations and reality. Center for Benefit-Cost Studies of Education, Teachers College, Columbia University, 138.

Hollands, F.M. and Tirthali, D., 2014. Why Do Institutions Offer MOOCs?. In Online Learning, 18(3), p.n3.

Kopp, M. and Lackner, E., 2014. Do MOOCs need a special instructional design. Proc. of EDULEARN14, 71387147.

Kukulska-Hulme, A., 2009. Will mobile learning change language learning? In ReCALL, 21(2), pp.157-165.

Lackner, E., Ebner, M. and Khalil, M., 2015. MOOCs as granular systems: design patterns to foster participant activity. In eLearning papers, (42), pp.28-37.

Littlejohn, A. and Milligan, C., 2015. Designing MOOCs for professional learners: Tools and patterns to encourage self-regulated learning. In eLearning Papers, 42.

Liyanagunawardena, T.R., Lundqvist, K., Mitchell, R., Warburton, S. and Williams, S.A., 2019. A MOOC taxonomy based on classification schemes of MOOCs. European Journal of Open, Distance and E-learning, 22(1).

Pilli, O. and Admiraal, W., 2016. A taxonomy of massive open online courses. In Contemporary Educational Technology, 7(3), pp.223-240.

Sharples, M., Delgado Kloos, C., Dimitriadis, Y., Garlatti, S. and Specht, M., 2015. Mobile and accessible learning for MOOCs. In Journal of interactive media in education, 1(4), pp.1-8.

Staubitz, T., Petrick, D., Bauer, M., Renz, J., and Meinel, C. (2016, April). Improving the peer assessment experience on MOOC platforms. Proc. of the third (2016) ACM conference on Learning@ Scale, pp.389-398.

Stöhr, C., Eriksson, T. and Adawi, T., 2015, June. Reasons for engaging in MOOC development: Management, faculty and support perspectives. In MOOCs in Scandinavia Conference. Stockholm, Sweden.

Tirthali, D., 2016. Are MOOCs Sustainable?. Corte \& U. Teichler (Eds.), From Books to MOOCs, pp.115-123.

Yuan, L. and Powell, S.J., 2013. MOOCs and open education: Implications for higher education. CETIS white paper.

Vigentini, L. and Zhao, C., 2016, April. Evaluating the'Student'Experience in MOOCs, pp.161-164. 